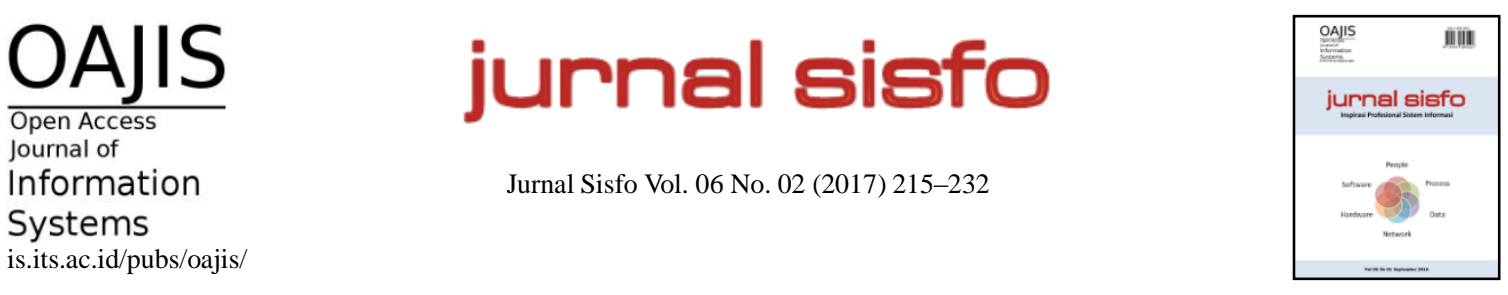

\title{
Studi Kelayakan Aplikasi Sales Force Automation pada PT. Semesta Nustra Distrindo
}

\author{
Janandra Aji Prayuda, Joko Lianto Buliali* \\ Program Studi Manajemen Teknologi Informasi, Institut Teknologi Sepuluh November
}

\begin{abstract}
In the implementation of Application Sales Force Automation (SFA) often occurs problems by actors in the organization that cause wastage of time and costs. It needs to be developed to make the system more accurate and efficient. However, before the development of the system is done, it is necessary to analyse its feasibility first. The feasibility analysis is carried out by the method of Cost Benefit Analysis(CBA). Some CBA methods used are payback period (PP), Net Present Value (NPV), Return on investment (ROI) and Interate These of Return (IRR). From the results of the feasibility of investment in PP 1 year 5 months earlier than estimated for 2 years, ROI of $36 \%$ and NPV for 2 years with interest rate of $10 \%$ per year is positive, ie Rp. 20,656,539.14. IRR the discount of bank's interest rate is $16.16 \%$. The results shows that the investment is feasible and acceptable.
\end{abstract}

Keywords: Sales Force Automation, Cost Benefit Analysis, Payback Period, Net Present Value, Return of Invesment, Interate Rute of Return

\begin{abstract}
Abstrak
Dalam implementasi Aplikasi Sales Force Automation (SFA) sering kali terjadi permasalahan-permasalahan oleh untuk pelaku di dalam organisasi yang menyebabkan pemborosan waktu dan biaya. Maka perlu dikembangkan dengan membuat sistem yang lebih akurat dan efisien, namun sebelum pengembangan sistem dilakukan maka perlu dianalisis kelayakan terlebih dahulu. Analisis kelayakan yang dilakukan adalah dengan metode Cost Benefit Analysis(CBA). Beberapa metode CBA yang digunakan adalah Payback Period (PP), Net Present Value (NPV), Return of Investment (ROI) dan Interate Rute of Return (IRR). Dari hasil kelayakan investasi dengan PP 1 tahun 5 bulan lebih cepat dari yang diperkiraan selama 2 tahun, $R O I$ sebesar $36 \%$ dan $N P V$ untuk 2 tahun dengan suku bunga $10 \%$ pertahun bernilai positif yaitu sebesar Rp. 20,656,539.14. IRR discount suku bunga bank yaitu 16.161\%. Dari hasil-hasil ini investasi layak dan dapat diterima.
\end{abstract}

Kata kunci: Sales Force Automation, Analisis Biaya Manfaat, Payback Period, Net Present Value, Return of Invesment, Interate Rute of Return

(C) 2017 Jurnal SISFO.

Histori Artikel : Disubmit 29 November 2016; Diterima 19 Januari 2017; Tersedia online 25 Januari 2017

*Corresponding Author

Email address: joko@if.its.ac.id (Joko Lianto Buliali) 


\section{Pendahuluan}

Sales Force Automation (SFA) adalah aplikasi yang digunakan untuk mengotomatisasi tugas penjualan , termasuk kegiatan penjualan, pemrosesan pesanan, manajemen pelanggan,forecast penjualan dan manajemen tenaga penjual dan untuk berbagi informasi [1]. PT. Semesta Nustra Distrindo (SND) adalah sebuah perusahaan yang bergerak dibidang distributusi makanan ringan. Kegiatan distribusi memiliki peranan cukup penting, karena dari kegiatan ditribusi tersebutlah, barang-barang kebutuhan manusia dari produsen dapat sampai ke tangan konsumen. Perusahaan ini memiliki banyak depo hampir di seluruh wilayah Indonesia. PT. SND memanfatkan aplikasi SFA yang digunakan para tenaga penjual dalam membantu akivitas penjualan melalui setiap outlet. Aplikasi SFA yang digunakan saat ini mengalami beberapa permasalahan dalam penerapannya di lapangan. Aplikasi ini masih kurang membantu kinerja tenaga penjual secara efektif dan efisien karena pada aplikasi yang digunakan belum bisa mencatat sales order secara easy to use seperti ditunjukan pada Gambar 1 dan pengecekan stok tidak dapat secara real time.
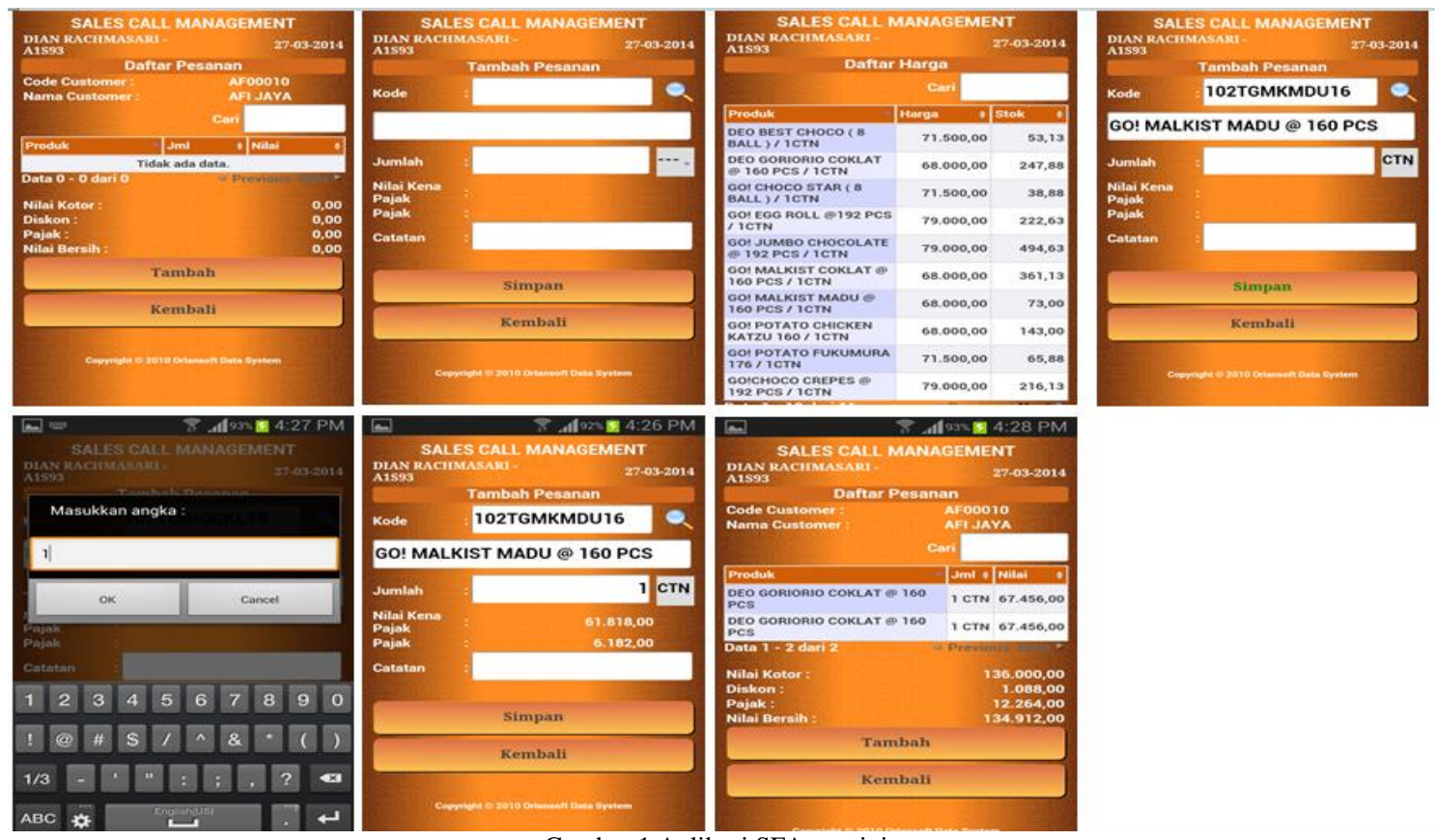

Gambar 1 Aplikasi SFA saat ini

Permasalahan lain pada manajemen persediaan yang juga kerap kali dihadapi dalam penggambil keputusan seperti pada Tabel 1 .

\begin{tabular}{lcccccccccccc}
\hline $\begin{array}{c}\text { Nama } \\
\text { Produk }\end{array}$ & Sat & Total & Mg11 & Mg12 & Mg13 & Mg14 & Mg15 & Mg16 & $\begin{array}{c}\text { Rata2 } \\
\mathbf{6} \text { Mg }\end{array}$ & $\begin{array}{c}\text { Rata2 } \\
\text { Ganjil }\end{array}$ & $\begin{array}{c}\text { Rata2 } \\
\text { Genap }\end{array}$ & $\begin{array}{c}\text { Saldo } \\
\text { Akhir }\end{array}$ \\
\hline $\begin{array}{l}\text { Leanet Ayam } \\
\text { BBQ @ 80 } \\
\text { PCS }\end{array}$ & CTB & 446 & 97 & 70 & 37 & 100 & 74 & 68 & 74 & 79 & 69 & 197 \\
$\begin{array}{l}\text { Leanet } \\
\begin{array}{l}\text { Sambal } \\
\text { Balado @8 }\end{array}\end{array}$ & СТВ & 176 & 42 & 25 & 59 & 38 & 5 & 7 & 29 & 23 & 35 & 1 \\
\hline
\end{tabular}




\begin{tabular}{|c|c|c|c|c|c|c|c|c|c|c|c|c|}
\hline $\begin{array}{c}\text { Nama } \\
\text { Produk }\end{array}$ & Sat & Total & Mg11 & Mg12 & Mg13 & Mg14 & Mg15 & Mg16 & $\begin{array}{l}\text { Rata2 } \\
6 \mathrm{Mg}\end{array}$ & $\begin{array}{l}\text { Rata2 } \\
\text { Ganjil }\end{array}$ & $\begin{array}{l}\text { Rata2 } \\
\text { Genap }\end{array}$ & $\begin{array}{l}\text { Saldo } \\
\text { Akhir }\end{array}$ \\
\hline $\begin{array}{l}\text { O-Potato } \\
2000 \mathrm{BBQ} \\
@ 60 \mathrm{PCS}\end{array}$ & СТВ & 21 & 0 & 0 & 0 & 5 & 6 & 10 & 7 & 8 & 6 & 29 \\
\hline $\begin{array}{l}\text { Potatos Ayam } \\
\text { BBQ @ } 80 \\
\text { PCS }\end{array}$ & СТВ & 51 & 19 & 19 & 3 & 8 & 7 & 11 & 9 & 7 & 10 & 107 \\
\hline $\begin{array}{l}\text { Potatos Sapi } \\
\text { Panggang } \\
@ 80 \text { PCS }\end{array}$ & СТВ & 42 & 7 & 7 & 4 & 9 & 8 & 9 & 7 & 8 & 6 & 110 \\
\hline $\begin{array}{l}\text { Leanet Tic-tic } \\
\text { Bawang@ } 80\end{array}$ & СТВ & 424 & 50 & 50 & 54 & 114 & 58 & 104 & 71 & 87 & 54 & 45 \\
\hline $\begin{array}{l}\text { Leanet Tic-tic } \\
\text { Smabal } \\
\text { Balado@ } 80\end{array}$ & СТВ & 219 & 47 & 47 & 22 & 51 & 33 & 49 & 37 & 39 & 34 & 27 \\
\hline $\begin{array}{l}\text { V-Tos } \\
\text { Kentang @ } \\
\text { 80 PCS }\end{array}$ & СТВ & 303 & 45 & 45 & 37 & 132 & 6 & 62 & 51 & 72 & 29 & 34 \\
\hline $\begin{array}{l}\text { V- Tos Sapi } \\
\text { Panggang@ } \\
80 \text { PCS }\end{array}$ & СТВ & 301 & 90 & 90 & 35 & 4 & 29 & 91 & 50 & 49 & 51 & 155 \\
\hline $\begin{array}{l}\text { Ketagi Ayam } \\
\text { Goreng@ } 40 \\
\text { PCS }\end{array}$ & СТВ & 30 & 3 & 3 & 5 & 7 & 4 & 9 & 5 & 6 & 4 & 120 \\
\hline $\begin{array}{l}\text { A- Extuder } \\
\text { Potato }\end{array}$ & & & & & & & & & & & & \\
\hline $\begin{array}{l}\text { Mister Bebeto } \\
60\end{array}$ & СТВ & 37 & 0 & 8 & 6 & 8 & 9 & 6 & 7 & 7 & 8 & 155 \\
\hline $\begin{array}{l}\text { Mister } \\
\text { Kentang } \\
\text { Goreng @ }\end{array}$ & СТВ & 876 & 96 & 130 & 114 & 261 & 114 & 161 & 146 & 184 & 108 & 935 \\
\hline $\begin{array}{l}\text { A- Mie } \\
\text { Kotak }\end{array}$ & & & & & & & & & & & & \\
\hline $\begin{array}{l}\text { Gemez Enak } \\
\text { Ayam Kecap }\end{array}$ & CTN & 213 & 33 & 31 & 19 & 21 & 74 & 35 & 36 & 29 & 42 & 381 \\
\hline $\begin{array}{l}\text { Mie Gemez } \\
\text { Ayam Goreng }\end{array}$ & CTN & 403 & 52 & 47 & 98 & 96 & 53 & 57 & 67 & 67 & 68 & 100 \\
\hline $\begin{array}{l}\text { Mie GeMez } \\
\text { Ayam } \\
\text { Panggang }\end{array}$ & CTN & 565 & 86 & 73 & 115 & 140 & 74 & 77 & 94 & 97 & 92 & 318 \\
\hline $\begin{array}{l}\text { A-Snack } \\
\text { Noodle }\end{array}$ & & & & & & & & & & & & \\
\hline $\begin{array}{l}\text { Spix Fujimie } \\
\text { Flavour Origi }\end{array}$ & СТВ & 13 & 6 & 6 & 1 & 0 & 0 & 0 & 4 & 6 & 4 & 1 \\
\hline $\begin{array}{l}\text { Spix Soba } \\
\text { Mie Sedap } \\
\text { Sambal }\end{array}$ & СТВ & 275 & 62 & 0 & 11 & 65 & 76 & 61 & 55 & 63 & 50 & 189 \\
\hline $\begin{array}{l}\text { Spix Soba } \\
\text { Mie Ayam } \\
\text { BBQ @8 }\end{array}$ & СТВ & 195 & 71 & 83 & 38 & 2 & 0 & 1 & 39 & 29 & 55 & 99 \\
\hline
\end{tabular}




\begin{tabular}{|c|c|c|c|c|c|c|c|c|c|c|c|c|}
\hline $\begin{array}{c}\text { Nama } \\
\text { Produk }\end{array}$ & Sat & Total & Mg11 & Mg12 & Mg13 & Mg14 & Mg15 & Mg16 & $\begin{array}{c}\text { Rata2 } \\
6 \mathrm{Mg}\end{array}$ & $\begin{array}{l}\text { Rata2 } \\
\text { Ganjil }\end{array}$ & $\begin{array}{l}\text { Rata2 } \\
\text { Genap }\end{array}$ & $\begin{array}{l}\text { Saldo } \\
\text { Akhir }\end{array}$ \\
\hline $\begin{array}{l}\text { Spix Soba } \\
\text { Mie Potato } \\
\text { BBQ }\end{array}$ & СТВ & 163 & 0 & 0 & 5 & 43 & 56 & 59 & 41 & 51 & 31 & 87 \\
\hline $\begin{array}{l}\text { Spix Mie } \\
\text { Goreng } \\
\text { BBQ@ } 80\end{array}$ & CTB & 88 & 8 & 6 & 11 & 22 & 26 & 15 & 15 & 14 & 15 & 118 \\
\hline $\begin{array}{l}\text { Suki Mie } \\
\text { Ayam Kecap } \\
@ 60\end{array}$ & СТВ & 30 & 3 & 7 & 5 & 4 & 4 & 7 & 5 & 6 & 4 & 124 \\
\hline $\begin{array}{l}\text { K-Pop } \\
\text { Seaweed @ } \\
60 \text { PCS }\end{array}$ & СТВ & 140 & 19 & 41 & 20 & 17 & 17 & 26 & 23 & 28 & 19 & 398 \\
\hline $\begin{array}{l}\text { Spix Fujimie } \\
\text { Goreng BBQ } \\
@ 80\end{array}$ & СТВ & 15 & 3 & 10 & 2 & 0 & 0 & 0 & 5 & 10 & 3 & 0 \\
\hline $\begin{array}{l}\text { Spix Mie } \\
\text { Goreng } \\
\text { Sambal } \\
\text { Balado }\end{array}$ & СТВ & 139 & 23 & 24 & 14 & 19 & 36 & 23 & 23 & 22 & 24 & 267 \\
\hline A-Twist & & & & & & & & & & & & \\
\hline $\begin{array}{l}\text { Jari-jari } \\
\text { Janggung } \\
\text { BBQ@80 P }\end{array}$ & CTB & 80 & 15 & 10 & 11 & 18 & 13 & 13 & 13 & 14 & 13 & 115 \\
\hline A-Biscuit & & & & & & & & & & & & \\
\hline $\begin{array}{l}\text { Goriorio Mix } \\
160\end{array}$ & CTN & 280 & 64 & 23 & 39 & 68 & 48 & 38 & 47 & 43 & 50 & 98 \\
\hline $\begin{array}{l}\text { Goriorio } \\
\text { Super Biscuit } \\
160\end{array}$ & CTN & 371 & 6 & 0 & 0 & 159 & 72 & 134 & 93 & 147 & 39 & 36 \\
\hline $\begin{array}{l}\text { Deo Best } \\
\text { Choco@160 } \\
\text { PCS }\end{array}$ & $\mathrm{CTN}$ & 378 & 60 & 75 & 46 & 78 & 50 & 69 & 63 & 74 & 52 & 378 \\
\hline
\end{tabular}

Terdapat tiga item yang ditandai dengan warna kuning memiliki stok yang sangat minimum bahkan ada produk stok yang mencapai 0 . Hal ini akan sangat memprihatinkan jika tidak terdapat permintaan dari pelanggan tetapi stok tidak ada. Oleh karenanya diharapkan terjadi keseimbangan dalam pengadaan persediaan sehingga biaya dapat ditekan seminimal mungkin dan dapat memperlancar jalannya proses produksi atau penjualan [2]. Perusahaan ini memutuskan untuk melakukan investasi di bidang IT, yaitu dengan melakukan pengembangan aplikasi SFA, dengan tujuan awal untuk mengatasi permasalahanpermasalahan diatas. Namun perlu dianalisis kelayakan terlebih dahulu proyek pengembangan aplikasi SFA. Analisis kelayakan investasi ini menggunakan metode Cost Benefits Analysis(CBA), yang mana metode ini dapat mengidentifikasi dan mengkonversikan komponen-komponen penilaian yaitu biaya-biaya dan manfaat-manfaat kedalam nilai ekonomis atau nilai yang bisa diukur dengan uang yang dihasilkan dari pengembangan aplikasi SFA. Kemudian hasil dari CBA dapat diketahui investasi pengembangan aplikasi SFA tersebut layak dan dapat diterima. 


\section{Tinjauan Pustaka/Penelitian Sebelumnya}

\subsection{Sales Force Automation (SFA)}

Sales Force Automation (SFA) adalah aplikasi yang digunakan untuk mengotomatisasi tugas penjualan, termasuk kegiatan penjualan, pemrosesan pesanan, manajemen pelanggan, forecast penjualan dan manajemen tenaga penjual dan untuk berbagi informasi [1].

SFA tidak mampu berdiri sendiri. Ada banyak aspek yang mendukung jalannya SFA. Dari diagram pada Gambar 2 dapat diketahui bahwa SFA tidak bisa berjalan hanya dengan vendor software namun SFA juga membutuhkan hardware sebagai wadah untuk menjalankan software tersebut. Selain itu, proyek SFA yang sudah kompleks kerap membutuhkan koneksi internet.

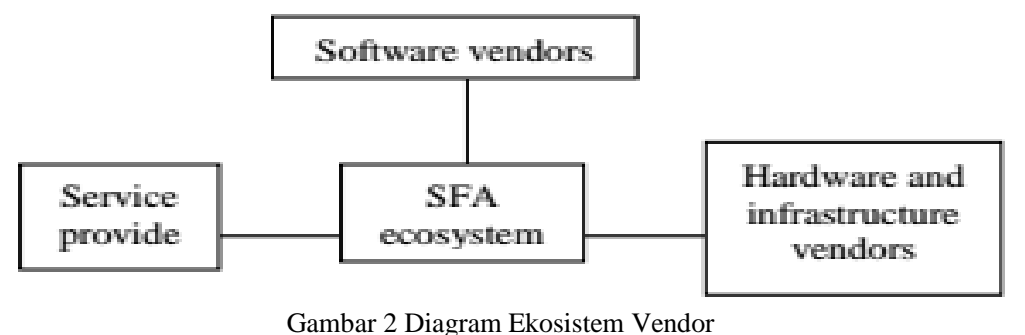

\subsection{Peramalan}

Peramalan atau yang biasa disebut forecasting adalah suatu kegiatan yang dilakukan untuk memperkirakan apa yang akan terjadi pada masa yang akan datang. Peramalan (forecasting) adalah seni dan ilmu untuk memperkirakan kejadian dimasa depan [3]. Biasanya peramalan dilakukan untuk memperkirakan sejumlah kebutuhan atau permintaan yang akan dipesan konsumen pada periode selanjutnya.

\subsection{Persediaan}

Adanya persediaan karena direncanakan atau karena tidak diketahuinya suatu informasi. Persediaan dapat diartikan sebagai barang-barang yang disimpan untuk digunakan atau dijual pada masa atau periode yang akan datang [2].

\subsubsection{Safety Stock}

Safety stock adalah persediaan tambahan yang diadakan untuk melindungi atau menjaga kemungkinan terjadinya kekurangan bahan (Out of Stock). Kemungkinan terjadinya Out of Stock dapat disebabkan karena penggunaan bahan baku yang lebih besar daripada perkiraan semula, atau keterlambatan dalam penerimaan bahan baku yang dipesan [4].

\subsubsection{Reorder Point}

Reorder point (ROP) adalah titik pemesanan kembali dimana adanya asumsi bahwa permintaan terjadi secara terus menerus dan kontinyu sehingga mengurangi tingkat jumlah persediaan yang ada [5]. 


\subsubsection{Economic Order Quantity}

Economic Order Quantity (EOQ) merupakan volume atau jumlah pembelian yang paling ekonomis untuk dilaksanakan pada setiap kali pembelian. Untuk memenuhi kebutuhan itu maka dapat diperhitungkan pemenuhan kebutuhan (pembeliannya) yang paling ekonomis yaitu sejumlah barang yang akan dapat diperoleh dengan pembelian dengan menggunakan biaya yang minimal [6].

\subsection{Key Performance Indicator}

Performa sales force perlu dikelola dengan baik agar bisa menunjang manajemen distributor secara keseluruhan. Sales force adalah ujung tombak perusahaan [7]. Jika kinerjannya buruk, hal itu akan berdampak pada kelangsungan suatu perusahaan. Oleh sebab itu, distributor yang baik akan selalu memperhatikan bagian ini sedemikian rupa agar memberikan kontribusi maksimal. Supaya bisa mengukur sejauh mana mereka memberikan kotribusi, salah satunya adalah dengan menggunakan penilaian atas prestasi kerja mereka. Pengukuran kinerja dalam rangka mengetahui tingkat keberhasilan/kegagalan pencapaian sasaran dilakukan dengan cara membandingkan antara realisasi dengan target setiap indikator kinerja yang telah ditetapkan. Performance indicator inilah yang akan menjadi point penilai sales force. Jadi, mengapa perform sales force perlu dikelola, salah satunya adalah untuk meningkatkan kinerja sales force [7].

\subsection{Analisis Kelayakan}

Salah satu tantangan terbesar dalam menilai kelayakan sebuah investasi pembangunan teknologi informasi adalah menilai atau memperkirakan manfaat apa yang akan diperoleh oleh perusahaan nantinya [8]. Dalam pengembangan sistem informasi sering kali terjadi permasalahan-permasalahan oleh untuk pelaku didalam organisasi yang menyebabkan pemborosan waktu dan biaya [9]. Dikatakan sebagai tantangan karena kebanyakan manfaat yang diberikan oleh teknologi informasi bersifat intangible atau sulit dikuantifikasikan ke dalam satuan angka finansial dan tidak secara langsung berpengaruh terhadap profitabilitas perusahaan. Studi kelayakan bisnis akan menyangkut tiga aspek yaitu, aspek manfaat ekonomis bagi usaha itu sendiri, aspek manfaat ekonomis usaha tersebut bagi negara tempat usaha tersebut dilaksanakan, dan aspek manfaat sosial usaha tersebut [10].

\subsection{Cost Benefit Analisis}

Secara umum, Cost Benefit Analysis (CBA) adalah cara untuk menentukan apakah hasil yang menguntungkan dari sebuah alternatif, akan cukup untuk dijadikan alasan dalam menentukan biaya pengambilan alternatif [11]. Analisa ini telah dipakai secara luas dalam hubungannya dengan proyek pengeluaran modal. Khususnya untuk dunia teknologi informasi, CBA adalah suatu teknik yang paling umum untuk menghitung biaya (cost) dan keuntungan/manfaat (benefit) dalam suatu proyek teknologi informasi. Untuk dapat melaksanakan CBA, kita harus menentukan hal-hal tersebut sebagai suatu cost dan benefit. Pada dasarnya, metode pengukuran dan analisa cost-benefit didasarkan pada cara serta perspektif manajemen manajemen dalam menilai kinerja teknologi informasi yang diimplementasikan [9].

\subsection{Komponen Cost Benefit Analysis}

Menurut Frederick yang dikutip dalam [12], komponen biaya yang berhubungan dengan pengembangan sebuah sistem informasi dapat diklasifikasikan dalam empat kategori yaitu :

1) Procurement Cost atau biaya pengadaan adalah semua biaya yang dikeluarkan berkaitan dengan pengadaan hardware. Diantaranya adalah seperti biaya konsultasi pengadaan hardware, pembelian 
hardware, instalasi hardware, manajerial dan personalia untuk pengadaan hardware. Biaya ini biasanya dikeluarkan pada tahun-tahun pertama (initial cost) sebelum sistem dioperasikan.

2) Start Up Cost merupakan biaya operasional yaitu semua biaya yang dikeluarkan sebagai upaya membuat sistem siap untuk dioperasikan. Biaya tersebut meliputi biaya pembelian, networking, reorganisasi, manajemen dan personalia.

3) Project Related Cost merupakan biaya yang berkaitan dengan biaya pengembangan sistem dan penerapannya. Biaya proyek antara lain adalah biaya dokumentasi, biaya rapat, biaya sistem analisis, manajerial dan personalia.

4) Ongoing Cost merupakan biaya operasional sistem agar sistem dapat beroperasi dengan baik. Termasuk biaya maintenance sistem. Biaya yang termasuk ongoing cost antara lain biaya personalia, biaya overhead (telepon, listrik, dll), perawatan software, biaya manajerial dalam operasional sistem. Biaya ini terjadi secara rutin selama usia operasional sistem

\subsection{Metode dalam Cost Benefit Analysis}

Adapun metode-metode yang dapat digunakan dalam cost benefit analysis ini adalah :

\subsubsection{Payback Period}

Payback period (PP) adalah jangka waktu tertentu yang menunjukkan terjadinya arus penerimaan (cash in flows) secara kumulatif sama dengan jumlah investasi dalam bentuk present value [13]. Secara singkat, formula untuk menghitung PP.yaitu:

$P P=\frac{\text { investasi }}{\text { kas_bersih }} \times 12$ bulan

\subsubsection{Return On Invesment (ROI)}

Return On Invesment (ROI) adalah total nilai biaya yang diinvestasikan (ditanamkan pada sebuah bisnis) telah kembali, yang berasal dari akumulasi keuntungan setiap bulannya [13]. Secara singkat, formula untuk menghitung ROI, yaitu:

$R O I=\frac{\text { laba_bersih }}{\text { total_investasi }} \times 100 \%$

\subsubsection{Net Present Value (NPV)}

Net Present Value merupakan metode yang membandingkan keseluruhan pengeluaran dengan keseluruhan penerimaan pada tingkat bunga tertentu [13]. Secara singkat, formula untuk menghitung NPV,yaitu:

$N P V=-$ nilai proyek + proceed $-1 /(1+i)^{1}+\ldots+$ proceed $-n /(1+i)^{n}$

Dengan kriteria:

1) Bila $N P V \geq 0$, maka usaha tersebut layak dilaksanakan

2) Bila $N P V<0$, maka usaha tersebut tidak layak dilaksanakan

\subsubsection{Internal rate of return (IRR)}

Internal rate of return adalah suatu tingkat discount rate yang menghasilkan net present value sama dengan nol. Dengan demikian apabila hasil perhitungan lebih besar dari discount rate usaha tersebut layak 
diterima dan akan ditolak jika hasil perhitungan lebih kecil dari tingkat discount rate [13]. Secara singkat, formula untuk menghitung IRR yaitu:

$\operatorname{IRR}=i_{1} \frac{N P V_{1}}{\left(N P V_{1}-N P V_{2}\right)} x\left(i_{1}-i_{2}\right)$

Dengan kriteria:

1) Bila $I R R>$ tingkat suku bunga berlaku, maka usaha tersebut layak dilaksanakan

2) Bila $I R R<$ tingkat suku bunga berlaku, maka usaha tersebut tidak layak dilaksanakan.

\section{Metodologi}

Tahapan dalam metodologi penelitian yaitu studi literatur, pengumpulan dengan proses wawancara dan pengumpulan dokumen, klasifikasi data dan analisa data dengan proses pembuatan flow process dan pengolahan data dengan metode CBA. Langkah metodologi seperti ditunjukan pada Gambar 3.

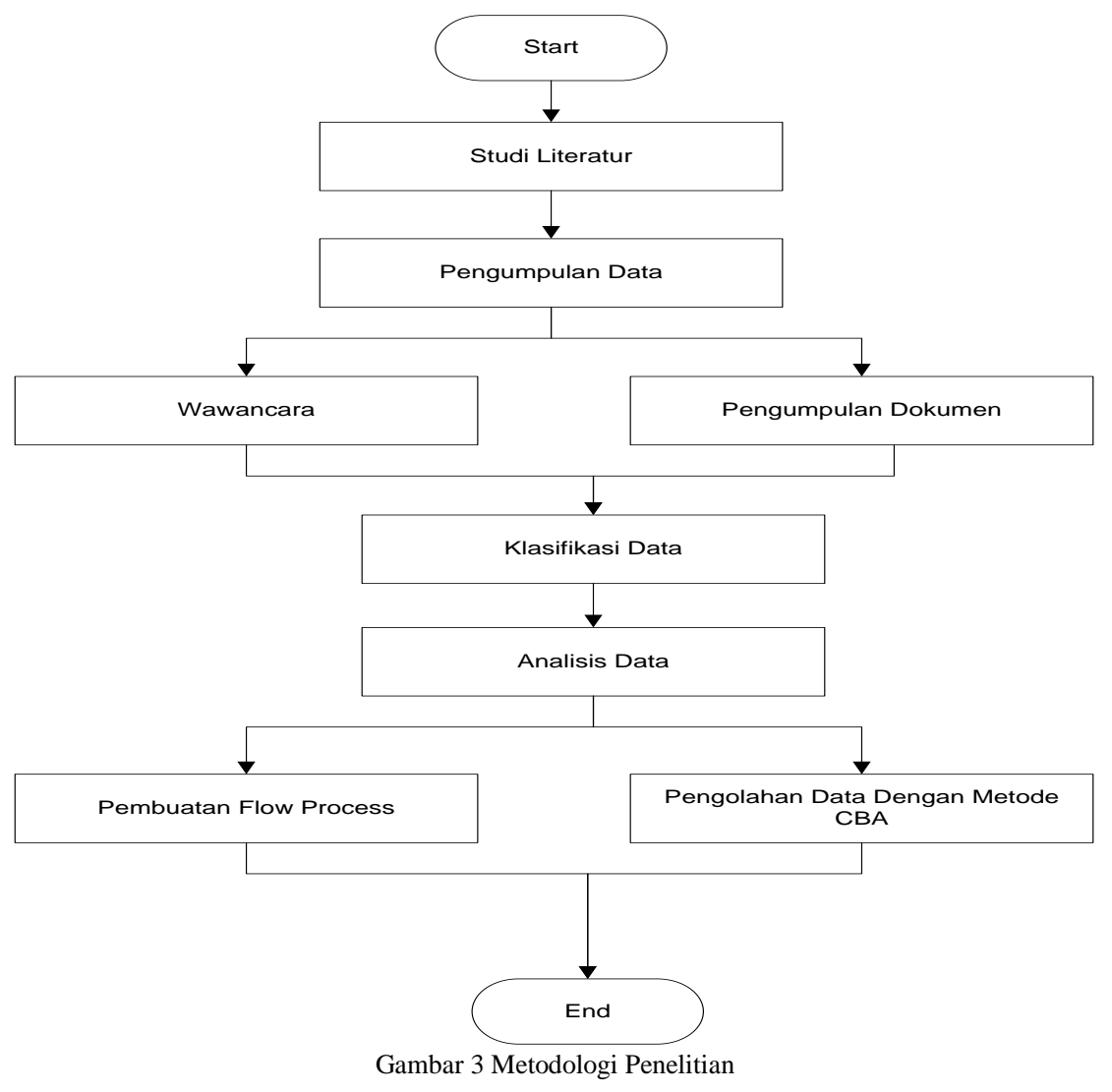

\subsection{Studi Literatur}

Studi literatur yang dilakukan dalam pembuatan paper ini adalah pembelajaran dan pemahaman literatur yang berkaitan dengan permasalahan yang ada. 


\subsection{Pengambilan Data}

Pada tahap ini dilakukan pengambilan data berupa apa saja yang terkait dengan aplikasi yang akan diinvestasikan oleh perusahaan. Pengambilan data dilakukan di PT. SND dan dilakukan dengan cara berikut :

\subsubsection{Wawancara}

Wawancara ini dilakukan untuk menggali aktivitas utama dengan pengembangan aplikasi SFA. Dengan memberikan beberapa pertanyaan kepada dua responden yaitu: staf tenaga penjual dan manajer EDP dari PT. SND, berikut pertanyaan yang diberikan:

1) Apakah aplikasi SFA yang berjalan saat ini sudah menghasilkan output yang sesuai dengan tujuan perusahaan? Jika belum apa kendalanya?

2) Proses Input transaksi penjualan seperti apa yang dapat memenuhi kebutuhan?

3) Sumber data stok yang bagaimana yang dibutuhkan dapat memenuhi kebutuhan tenaga penjual?

4) Bagaimana cara PT. SND mengolah forecast penjualan, manajemen persediaan dan purchase order agar tidak kehabisan stok?

\subsubsection{Pengamatan Dokumen}

Dari proses wawancara dapat diketetahui beberapa kendala yang sedang dialami dalam penerapan aplikasi SFA sehingga dapat mengetahui arah dari proses pengembangan sistem selanjutnya dan dapat melakukan pengamatan dokumen. Pengamatan dokumen dilakukan terhadap dokumen-dokumen terkait dengan pengembangan aplikasi SFA pada PT. SND.Dokumen yang berupa kebutuhan dari pengembangan dan dokumen yang berhubungan dengan manfaat yang didapatkan dari pengembangan sistem.

1) Dokumen Kebutuhan Pengembangan Sistem

Dokumen ini berisi beberapa price list untuk kebutuhan pengembangan sistem dari harga penambahan server baru untuk aplikasi SFA, kebutuhan operasinal jaringan, akses internet, kontrak programmer, komputer untuk programmer dan untuk proses traning kepada pengguna.

2) Dokumen Proses Yang berjalan Saat Ini

Dokumen ini diamati melalui proses yang sedang berjalaan saat ini yang mengalami kendala dalam penerapan SFA. Pada proses input transaksi penjualan yang tidak easy to use sehingga tenaga penjual harus di-input manual dahulu kemudian disalin kedalam aplikasi. Kemudian data stok yang tidak secara real time sehingga jika tidak ada stok sales order harus dibatalkan. Dan permasalahan manajemen persediaan untuk menyimpan sejumlah barang agar setiap permintaan pelanggan dapat terpenuhi. Dengan mengamati dokumen ini diharapkan dapat mengetahui manfaat dari pengembangan sistem.

\subsection{Klasifikasi Data}

Klasifikasi Data yang diperoleh melalui tahapan pengumpulan data kemudian diklasifikasikan sesuai dengan kebutuhan dari framework metode CBA. Tujuan dari klasifikasi data adalah mengelompokan mana data sebagai komponen biaya dan komponen manfaat. Data dari dokumen kebutuhan pengembangan sistem diklasifikasikan dapat menjadi komponen biaya dan dokumen proses saat ini diklasifikaskan dapat menjadi komponen manfaat dan sesuai dengan kebutuhan dari framework metode CBA. 


\subsection{Analisis Data}

Pada tahap ini dilakukan analisi data pada data yang telah diklasifikasikan. Tujuan dari analisis data adalah untuk mendeskripsikan data dengan diolah menggunakan metode CBA, sehingga bisa dipahami, lalu untuk membuat kesimpulan atau menarik kesimpulan. Analisis data dilakukan dengan cara berikut :

\subsubsection{Pembuatan Rancangan Flow Proses}

Pembuatan rancangan flow process pengembangan aplikasi SFA sebagai pattern pengembangan aplikasi yang akan dilakukan perbaikan dan penambah layanan untuk solusi dari permasalahan yang terdapat pada pendahuluan

\subsubsection{Pengolahan Data dengan Metode CBA.}

Data yang telah diklasifikasikan dan hasil dari rancangan flow prosess untuk diolah menjadi informasi dengan tujuan data tersebut bisa dipahami dan bermanfaat untuk solusi permasalahan, tertutama masalah yang pada pendahuluan. Kemudian berdasarkan pattern dari flow proses data diolah dengan metode CBA untuk menentukan apakah investasi untuk pengembangan aplikasi SFA ini layak dan dapat diterima.

\section{Hasil dan Pembahasan}

\subsection{Hasil}

Hasil dari penelitian terdiri dari rancangan flow process sebagai pattern pengembangan aplikasi SFA, identifikasi biaya dan manfaat

\subsubsection{Rancangan Flow Proses}

Rancangan flow proses ini berasal dari hasil klaisfikasi data ini dapat menggabarkan aplikasi yang sudah ada saat ini dengan melakukan perbaikan dan penambahan pada beberapa layanan yang dapat memudahkan pengguna dan membantu proses bisnis dari perusahaan. Flow process ini juga sebagai pemetaan pattern dari identifikasi biaya dalam mengestimasi biaya investasi seperti lama kontrak programmer, pengadaan server baru aplikasi SFA, kebutuhan jaringan server dan internet sampai pada training aplikasi. Pemetaan pattern untuk identifikasi manfaat dengan adanya perbaikan dan penambahan layanan sehingga bermanfaat dalam pengehamatan biaya atau peningkatan produktivitas pegawai diajadikan sebagai arus kas masuk perusahaan.

Flow process rancangan aplikasi dengan langkah-langkah adalah sebagai berikut (lihat Gambar 4):

1) Pertama manajer tenaga penjual melakukan login pada aplikasi.

2) Manajer tenaga penjual membuat forecast penjualan. Forecast penjualan merupakan suatu dugaan terhadap permintaan yang akan datang berdasarkan pada beberapa variabel peramal, sering berdasarkan data deret waktu historis [12]. Forecast penjualan untuk seminggu kedepan melaui data penjualan 6 minggu kebelakang. Aplikasi menghitung tiga jenis rata-rata yaitu rata-rata selama 6 minggu, rata-rata minggu ganjil dan rata-rata minggu genap dalam 6 minggu. Kemudian manajer memilih rata-rata penjualan.

3) Perhitungan rata-rata ini merupakan ketentuan dari PT. SND juga merupakan salah satu metode forecast penjualan yaitu metode single single moving average, dimana perhitungan ini meliki salah satu ciri yaitu Untuk membuat forecast memerlukan data historis selama jangka waktu tertentu [15]. 
4) Setelah memilih rata-rata, aplikasi akan melakukan proses inventory control atau manajemen persediaan. Tujuan dari manajemen persediaan adalah untuk menjaga persediaan pada tingkat yang optimal sehingga diperoleh penghematan-penghematan untuk persediaan tersebut [2].

5) Data forecast penjualan sebagai dasar melakukan proses manajemen persediaan dengan menghitung safety stock dan ROP sehingga ketika stok mencapai ROP aplikasi akan menghitung EOQ dan melakukan purchase order sesuai perhitungan EOQ secara otomatis.

6) Kemudian membuat standard key performance indicator (KPI) dari data forecast penjualan standar terdiri dari kunjungan dan penjualan. Data standard KPI ini disimpan database.

7) Membuat jadwal kunjungan tenaga penjual ke outlet. Data standard KPI ini disimpan database

8) Tenaga penjual melakukan kunjungan dan penjualan ke outlet.

9) Hasil kunjungan dan penjualan tenaga penjual akan di monitoring oleh manajer tenaga penjual.

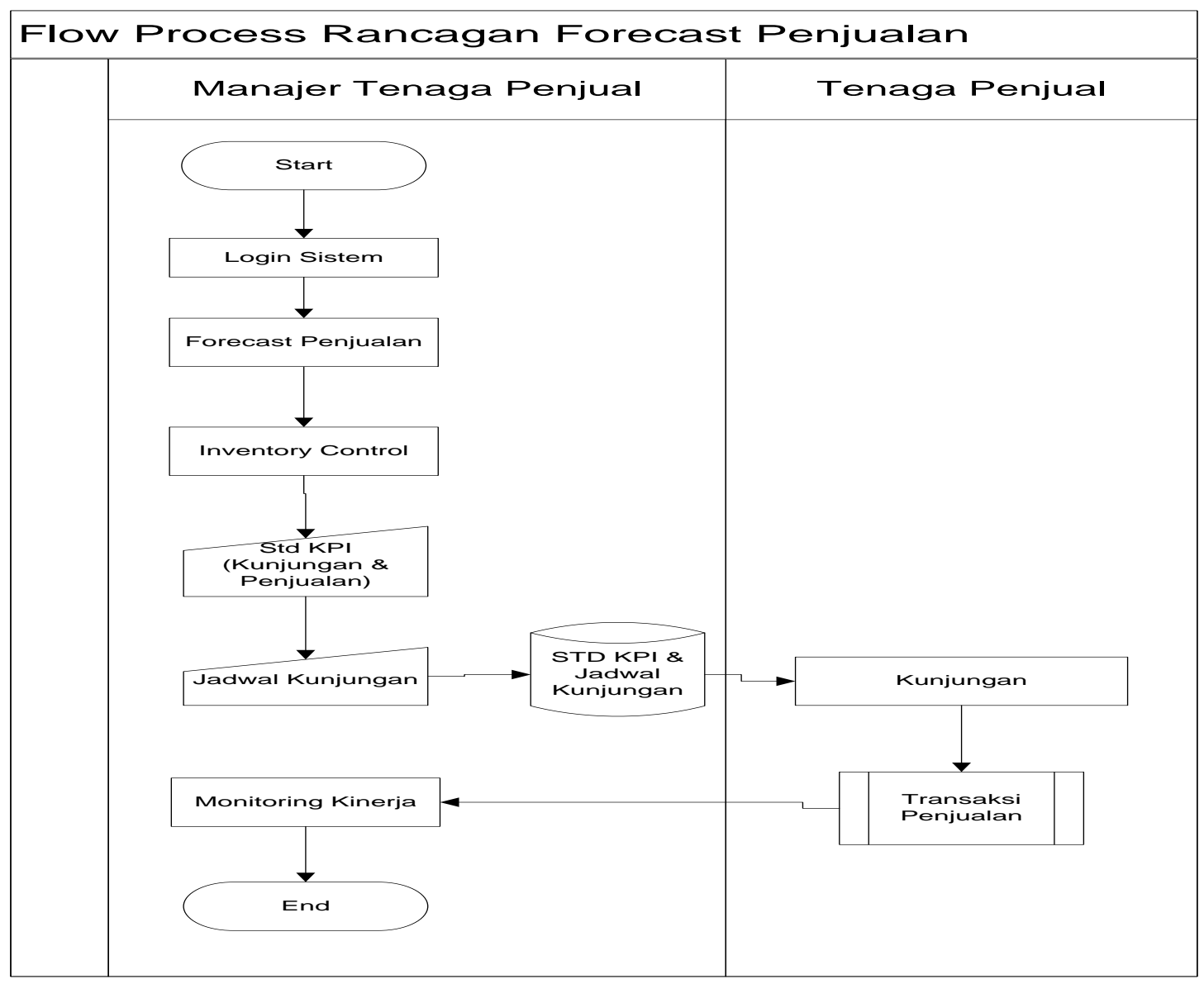

Gambar 4 Flow Proces Rancangan Forecast Penjualan

Flow process rancangan transaksi penjualan dengan langkah-langkah adalah sebagai berikut (lihat Gambar 5):

1) Pertama tenaga penjual melakukan login pada Aplikasi. Proses login pada tenaga penjual ini juga otomatis mengidetifikasi nomer imei handphone yang telah didaftarkan pada aplikasi sehingga login hanya bisa dilakukan pada tools yang telah disediakan perusahaan. Nomer imei adalah singkatan dari International Mobile Station Equipment Identity. IMEI terdiri dari 15 digit angka, membawa informasi tentang ponsel yang bersangkutan seperti pabrik pembuat ponsel, model ponsel, dsb bersifat unik akan 
berbeda dengan tiap ponsel. Sehingga jika menggunakan tools lain tenaga penjual tidak bisa masuk dalam aplikasi.

2) Pilih outlet aplikasi otomatis mengidentifikasi koordinat lokasi dari tenaga penjual. Hal ini akan tersimpan dalam aplikasi sebagai kontrol kunjungan tenaga penjual dengan menggunakan GPS.

3) Terdapat pilihan cek jatuh tempo hutang jika terdapat hutang lanjut ke proses nomer 4. Jika tidak lanjut ke proses nomer 5 .

4) Bayar hutang jika iya dapat melakukan transaksi lanjut ke proses nomer 8 , jika tidak proses selesai.

5) Tampilkan detail produk yanga akan dipesan.

6) Terdapat pilihan cek stok jika stok ada lanjut proses input SO, data sales order ini disimpan dalam database. Jika tidak ada stok terdapat pilihan input sebagai input transaksi sebagai pesanan penjualan. Data pesanan ini disimpan dalam database.

7) Bagian administrasi penjualan menyetujui atau approve SO yang telah dimasukkan oleh tenaga penjual untuk diproses selanjutnya ke bagian logistik.

8) Bagian logistik membuatkan surat jalan untuk mengirimkan pesanan pada pelanggan dan proses selesai.

9) Outlet sebelumnya melakukan registrasi sebagai rekanan PT. SND, kemudian dapat login pada aplikasi untuk melihat produk dan melakukan pemesanan produk

10)Pemesanan produk ini akan mengecek jatuh tempo hutang jika terdapat hutang agar melunasi hutang terlebih dahulu. Jika tidak lanjut ke proses 12. Dengan adanya fitur pemesanan produk dan pesanan penjualan jika stok tidak tersedia diharapkan memenuhi kepuasan pelanggan. Kepuasan pelanggan adalah sejauh mana manfaat sebuah produk dirasakan(perceived) sesuai dengan apa yang diharapkan pelanggan [16].

11)Rekanan atau outlet melunasi hutang jika iya lanjut ke proses nomer 17 jika tidak proses selesai.

12) Setelah outlet melihat detail produk dan dapat melakukan pesanan pembelian.

13)Lanjut proses nomer 6 .

\subsubsection{Identifikasi Biaya}

Start up cost merupakan biaya operasional yaitu semua biaya yang dikeluarkan sebagai upaya membuat sistem siap untuk dioperasikan. Biaya tersebut meliputi biaya pembelian, networking, reorganisasi, manajemen dan personalia (lihat Tabel 2).

Tabel 2. Start Up Cost

\begin{tabular}{lll}
\hline No & Nama & Cost \\
\hline 1 & $\begin{array}{l}\text { Biaya pemebelian CPU untuk programmer } \\
\text { buah }\end{array}$ & $4.000,000$ \\
2 & Biaya kebutuhan operasional jaringan & 3.000 .000 \\
3 & Biaya pembelian server baru & 80.235 .000 \\
4 & Biaya Internet dedicated & 6.500 .000 \\
5 & Biaya kontrak programmer 3 bulan & 13.500 .000 \\
6 & Biaya Training \& Foto copy Manual book & 6.760 .000 \\
\hline
\end{tabular}

Berikut detail penjelasan dari star up cost

1) Biaya awal untuk pengembangan aplikasi SFA yang baru, maka PT SND membutuhkan :

a. Kontrak programmer dengan nilai kontrak Rp. 4.500.000 dengan target penyelesaian pembuatan adalah 3 bulan pembuatan aplikasi sales force automation yang baru (termasuk uji coba)

b. Pengadaan 1 unit komputer untuk programmer Rp. 4.000.000,-

c. Biaya pengadaan 1 unit server untuk aplikasi SFA baru adalah Rp 80,235,000,- 
d. Biaya internet dedicated 3Mbps adalah Rp 6.500.000,-

e. Kebutuhan operasional jaringan server dan lain-lain Rp. 3.000.000,-

2) Biaya Training dan yang meliputi fotocopy untuk materi pelatihan dan manual book untuk 622 (tenaga penjual)+ 54 (Manajer tenaga penjual). 676X 10.0000=Rp. 6.760.000,-

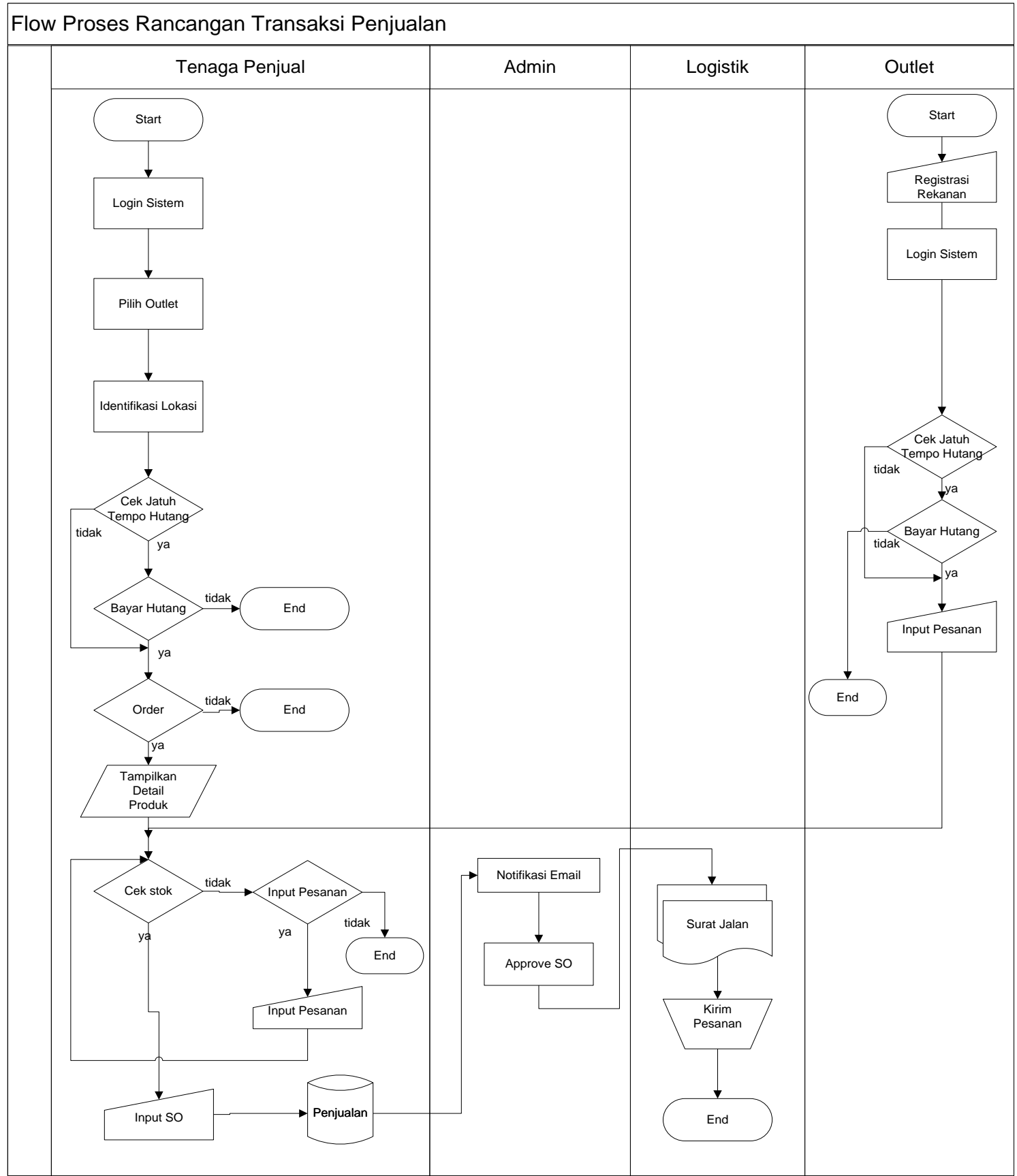

Gambar 5 Flow Process Rancanga Transaksi Penjualan 


\subsubsection{Identifikasi Manfaat}

1) Manfaat Tangible. Merupakan keuntungan nyata yang dapat dikalkulasikan secara keuangan (keuangan ini lebih mengarah pada sisi bisnis perusahaan) [17]. Berikut detail penjelasan dari manfaat tangible yang diperoleh perusahaan (lihat Tabel 3).

a. Keutungan Penghematan Biaya Administrasi

Dengan menggunakan pengembangan rancangan aplikasi memiliki keuntungan dengan penghematan biaya admintrasi. Karena pada keadaan aplikasi saat ini masih menggunakan pencatatan pesana secara manual sebelum diinputkan ke aplikasi hal ini dikarenakan aplikasi masih belum easy to use. Biaya administrasi adalah biaya untuk keperluan alat tulis alat tulis digunakan untuk mencatat penjualan. Dengan adanya aplikasi baru dapat menghemat biaya untuk alat tulis dalam pencatatan penjualan adalah Rp. 2.488.00/ bulan. Rincian sebagai berikut :

1. Kebutuhan alat tulis untuk 622 tenaga penjual (yang tersebar pada 54 depo).

2. Harga alat tulis Rp. 4000

3. Total kebutuhan adalah $622 \times 4000=$ Rp. 2.488.000,-

b. Keutungan Penghematan Pengurangan Staf Admin Purchase Order

Dengan menggunakan pengembangan rancangan aplikasi memiliki keuntungan dengan mengurangi jumlah staf administrasi purchasing dari 2 menjadi 1 untuk bagian input purchase order produk yang dijual PT SND. Hal ini dapat dilakukan administrasi untuk proses input purchase order karena aplikasi telah otomatis purchase order ketika melakukan proses forecast penjualan. Sehingga dapat dihemat Rp. 3.040.000,-/bulan.

c. Keutungan Pengurangan Komputer Staf Admin Purchase Order

Dengan berkurangnya 1 staf admin purchase order untuk proses input purchase order maka dapat menghilangkan biaya listrik dari penggunan 1 komputer staf tersebut jika dikonversikan rupiah adalah sebagai berikut:

1. Penggunaan listik di kantor $200 \mathrm{KVa}$ untuk persatuan KWh adalah Rp 1.460

2. Penggunan Komputer 8 jam dengan 30 Watt dapat $(30: 1000) \mathrm{X} 8 \mathrm{jam}=0.24 \mathrm{KWh}$

3. Penggunaan dalam sehari jika dikonversikan dalam rupiah $=350.4$ perhari

Tabel 3. Manfaat Tangible

\begin{tabular}{lllll}
\hline No & Nama & Tahun 0 & Tahun 1 & Tahun 2 \\
\hline 1 & $\begin{array}{l}\text { Penghematan Biaya Administrasi tenaga penjual } \\
\text { @ Rp. 2.488.000/bulan }\end{array}$ & 0 & $29,856,000.00$ & $29,856,000$ \\
2 & $\begin{array}{l}\text { Penghematan pengurangan staf admin PO @ Rp. } \\
\text { 3.040.000/bulan }\end{array}$ & 0 & $36,480,000.00$ & $36,480,000$. \\
3 & $\begin{array}{l}\text { Penghematan Biaya Listrik 1 Komputer @ } \\
\text { Rp.350.4 /hari }\end{array}$ & 0 & $109,324.80$ & $109,324.80$ \\
\hline
\end{tabular}

2) Manfaat Intangible. Merupakan keuntungan yang lebih mengacu kepada efektifitas proses kerja yang sudah diterapkan dalam perusahaan [17]. Berikut detail penjelasan dari manfaat tangible (lihat Tabel 4). Keuntungan tersebut berupa Peningkatan Kinerja Tenaga Penjual.

Jika sebelumnya tenaga penjual membutuhkan waktu 20 menit karena harus mencatat manual pesanan terlebih dahulu kemudian keluar dari outlet dan disalin input transaksi kedalam aplikasi dengan menggunakan waktu kurang lebih 5 menit sehingga dapat melakukan penghematan 15 menit dalam 1 hari rata-rata tenaga penjual melakukan transaksi penjualan 10 penghematan sebanyak 150 menit. Dengan adanya aplikasi baru dapat menghemat biaya peningkatan kinerja adalah Rp. 36.538,45,- /hari, hal ini dapat dihemat dengan adanya proses input transaksi penjulan yang lebih easy to use. 
Jika dikonversikan perhitungan adalah sebagai berikut:

a. Gaji 1 staf tenaga penjual sebulan (26 hari kerja, dengan 8 jam kerja perhari). Rp. 3.040.000. Maka biaya perjam adalah Rp. 3.040.000/(26 X 8) = Rp. 14.615,38

b. Konversi hasil penghematan dalam jam 150 menit $/ 60=2,5$ jam

c. Total peningkatan kinerja tenaga penjual yaitu Rp. 14.615,38 X 2.5 Jam = Rp. 36.538,45

Tabel 4. Manfaat Intangible

\begin{tabular}{llllllll}
\hline No & Nama & & & & Tahun 0 & Tahun 1 & Tahun 2 \\
\hline 1 & $\begin{array}{l}\text { Penigkatan kinerja } \\
36.538,45,-/ \text { hari }\end{array}$ & tenaga & penjual & $@$ Rp. & 0 & $11,399,996.40$ & $11,399,996.40$ \\
\hline
\end{tabular}

\subsubsection{Perhitungan Metode Cost Benefit Analysis}

Rangkuman dari indentifikasi biaya dan identifikasi manfaat kemudian digabungakan untuk dilakukan perhitungan dengan metode cost benefit analysis dapat dilihat pada Tabel 5.

Tabel 5. Rangkuman Start Up Cost \& Benefit

\begin{tabular}{|c|c|c|c|}
\hline Nama & Tahun 0 & \multicolumn{2}{|c|}{ Tahun 2} \\
\hline \multicolumn{4}{|l|}{ Start up Cost } \\
\hline $\begin{array}{l}\text { Kontrak Kerja Programmer } 3 \text { Bulan @ Rp. } \\
4.500 .000\end{array}$ & $13,500,000$ & - & - \\
\hline Komputer Programmer & $4,000,000$ & - & - \\
\hline Server SFA & $80,235,000$ & - & - \\
\hline Dedicated Internet Server $3 \mathrm{Mbps}$ & $6,500,000$ & - & - \\
\hline $\begin{array}{l}\text { Kebutuhan Operational Jaringgan Server dan } \\
\text { lain-lain }\end{array}$ & $3,000,000$ & - & - \\
\hline Biaya Training \& Foto copy Manual book & $6,760,000$ & - & - \\
\hline Total Biaya & $113,995,000$ & - & - \\
\hline \multicolumn{4}{|l|}{ Manfaat Tangible } \\
\hline $\begin{array}{l}\text { Penghematan Biaya Administrasi tenaga penjual } \\
\text { @ Rp. 2.488.000/bulan }\end{array}$ & - & $29,856,000.00$ & $29,856,000.00$ \\
\hline $\begin{array}{l}\text { Penghematan pengurangan staf admin PO @ Rp. } \\
3.040 .000 \text { /bulan }\end{array}$ & - & $36,480,000.00$ & $36,480,000.00$ \\
\hline $\begin{array}{l}\text { Penghematan Biaya Listrik } 1 \text { Komputer @ } \\
\text { Rp.350.4 /hari }\end{array}$ & - & $109,324.80$ & $109,324.80$ \\
\hline \multicolumn{4}{|l|}{ Manfaat Intangible } \\
\hline $\begin{array}{l}\text { Penigkatan kinerja tenaga penjual @ Rp. } \\
36.538,45,- \text { /hari }\end{array}$ & - & $11,399,996.40$ & $11,399,996.40$ \\
\hline Total Benefit & $-113,995,000$ & $77,845,321.20$ & $77,845,321.20$ \\
\hline Sisa investaasi & $41,695,642$ & - & \\
\hline Periode pengembalian / Payback Period & 1 tahun & 5bulan & \\
\hline Pengembalian Investasi / Return of Investment & $36 \%$ & - & \\
\hline
\end{tabular}




\subsection{Pembahasan}

Dari hasil identifikasi biaya dan manfaat kemudian data diolah dengan metode dari CBA uji validitas kelayakan investasi sehingga dapat diketahui investasi pengembangan aplikasi SFA tersebut layak dan dapat diterima. Setiap organisasi memiliki proses dan format sendiri untuk melakukan studi kelayakan, tetapi kebanyakan menilai tiga area penting yaitu technical, economic dan operational [18]. Berikut metode CBA yang diterapkan.

1) Pembuktian dengan Payback Period (PP)

Rumus mencari payback period

Payback period $=$ Total Investasi $/$ Arus Kas Netto X 12 Bulan

Payback period $=113,995,000 / 77.845 .321 .20 \times 12$

$$
=17 \text { bulan }
$$

Payback period adalah suatu periode yang diperlukan untuk menutup kembali pengeluaran investasi (initial cash investment) dengan menggunakan aliran kas, dengan kata lain payback period merupakan rasio antara initial cash investment dengan cash inflow-nya yang hasilnyamerupakan satuan waktu. Selanjutnya nilai rasio ini dibandingkan dengann maximum payback period yang dapat diterima [19]. Payback period selama 1 tahun 5 bulan lebih cepat dibanding maximum payback period yaitu 2 tahun berarti investasi layak dan dapat diterima.

2) Pembuktian dengan Return of Investment

Rumus mencari return of investment

ROI $=($ Total Penjualan - Investasi $) /$ Investasi $x 100 \%$

$R O I=(155,690,642.40-113,995,000) / 113,995,000 \times 100 \%$

$R O I=36 \%$

Return of investment (ROI) $36 \%$ hal ini berarti bahwa jika PT. SND melakukan investasi untuk pengembembangan aplikasi baru sebesar Rp. 113,995,000 akan mendapat tingkat pengembalian $36 \%$. Dimana ROI merupakan kemampuan perusahaan untuk menghasilkan keuntungan yang akan digunakan untuk menutup investasi yang dikeluarkan [20]. Sehingga berdasarkan hasil analisis ROI maka pengembangan rancangan aplikasi SFA ini layak dilaksanakan.

3) Pembuktian dengan Net Present Value

Net present value selama 2 tahun dengan suku bunga $10.25 \%$ ( berdasarkan suku bunga dari PT. Bank Mandiri, Tbk)

$$
\begin{aligned}
& N P V=- \text { nilai proyek }+ \text { proceed }-1 /(1+i)^{1}+\ldots+\text { proceed }-n /(1+i)^{n} \\
& N P V=-113,995,000-+77.845 .321 .20 /(1+0,1025)^{1}+77.845 .321 .20 /(1+0,1025)^{2} \\
& N P V=20,656,539.14
\end{aligned}
$$

Net present value selama 2 tahun dengan suku bunga $10 \%$ ( berdasarkan suku bunga dari PT. Bank Mandiri, Tbk) sebesar Rp. 21,105,555. Kriteria suatu proyek investasi dapat diterima jika NPV lebih 
dari 0 (NPV > 0) dan suatu proyek akan ditolak jika NPV lebih kecil dari 0 (NPV < 0) [21]. Karena net present value untuk 2 tahun lebih besar dari nol (positip) berarti investasi pengembangan rancangan apliksi SFA ini dapat diterima.

4) Pembuktian dengan IRR

Net present value selama 2 tahun dengan suku bunga $13.50 \%$ ( berdasarkan suku bunga dari PT. Bank Mega, Tbk)

$$
\begin{aligned}
& N P V=- \text { nilai proye }+ \text { proceed }-1 /(1+i)^{1}+\ldots+\text { proceed }^{-} n /(1+i)^{n} \\
& N P V=-113,995,000-+77.845 .321 .20 /(1+0,135)^{1}+77.845 .321 .20 /(1+0,135)^{2} \\
& N P V=15,019,543.53
\end{aligned}
$$

Rumus IRR $=I_{1}+\left(N P V_{2} /\left(N P V_{1}-N P V_{2}\right)\right)+\left(I_{2}-I_{1}\right)$

IRR $=10.25+(15,019,543.53 /(20,656,539.14-15,019,543.53))+(13.5-10.25)$

$\mathrm{IRR}=16.16 \%$

Dikarenakan inventasi IT sangat tidak terduga sehingga di sumsikan suku bunga lebih tinggi yaitu $13.5 \%$ (berdasarkan suku bunga dari PT. Bank Mega, Tbk). Internal rute of return pada suku bunga $16.16 \%$ discount rate umumnya mengacu pada suku bunga bank besarnya antara $10.25 \%$ sampai dengan $13.5 \%$.Kriteria suatu proyek investasi dapat diterima jika IRR lebih besar dari tingkat diskonto (discount rate) dan akan ditolak jika IRR lebih kecil dari tingkat diskonto (discount rate) [21]. Dengan IRR sebesar $16.16 \%$ maka investasi pengembangan rancangan apliksi SFA ini dapat diterima.

Dari hasil kelayakan investasi dengan $P P 1$ tahun 5 bulan lebih cepat dari yang diperkiraan selama 2 tahun, ROI sebesar $36 \%$ dan NPV untuk 2 tahun dengan suku bunga $10.25 \%$ pertahun bernilai positif yaitu sebesar Rp20,656,539.14., dan IRR discount suku bunga bank yaitu 16.16\%. Dari hasil-hasil ini investasi pengembangan rancangan apliksi SFA layak dan dapat diterima. Studi kelayakan juga digunakan untuk mengetahui risiko yang terdapat dalam pengembangan sistem [22].

\section{Kesimpulan}

\subsection{Simpulan}

Dari hasil identifikasi manfaat dapat diambil manfaat dalam beberapa penghematan biaya diantaranya penghematan biaya dalam penghematan biaya administrasi, penghematan biaya untuk pengurangan 1 staf admin purchase order, biaya listik dari penggunaan komputer dan peningkatan kinerja tenaga penjual

Metode Cost Benefit Analysis dapat digunakan untuk mengukur kelayakan suatu proyek teknologi informasi. Terdapat 4 perhitungan dalam metode Cost Benefit Analysis yaitu Net Present Value (NPV), Return on Investment (ROI), Payback Period (PP), dan Internal Rate of Return (IRR). Dalam kasus pengembangan aplikasi SFA, didapatkan nilai NPV yaitu sebesar Rp 20,656,539.14, ROI sebesar 36\% dari total investasi, PP dengan jangka waktu 1 tahun 5 bulan dan IRR sebesar 16.16\%. Dari hasil-hasil ini investasi pengembangan rancangan apliksi SFA layak dan dapat diterima.

\subsection{Saran}

Dalam melakukan penilaian terhadap kelayakan suatu proyek teknologi informasi disarankan agar tidak melihat satu sisi ROI saja, tetapi perlu jugan juga diperhatikan komponen lain seperti PP, NPV dan IRR. 
Dari hasil penelitian studi kelayakan ini dapat digunakan sebagai referensi yang bermanfaat bagi penentuan investasi proyek pengembangan aplikasi SFA dan disesuaikan metode forecast dari perusahaan yang diteliti.

\section{Daftar Rujukan}

[1] Barker, R.M., 2009. Why is my sales force automation system failing? Proceedings of The Kelley School of Business Conference. Indiana University.

[2] Agus Ristono.2009. Manajemen Persediaan Edisi 1.Yogyakarta : Graha Ilmu

[3] Heizer, Jay dan Barry Render. 2009. Operations Management-Manajemen Operasi. Edisi 9 Buku 1.Jakarta : Salemba Empat

[4] Assauri, Sofyan, 1999. Manajemen Produksi dan Operasi, Edisi Revisi, LPFE-UI, Jakarta.

[5] Martono dan D. Agus Harjito. 2005. Manajemen Keuangan. Penerbit Ekonisia: Yogyakarta.

[6] Indriyo Gitosudarmo. 2002. Managemen Keuangan. Edisi keempat. Yogyakarta: Penerbit BPFE

[7] Royan, F.M. (2009). Distributorship Management, Jakarta: PT.Gramedia Pustaka Utama

[8] Indrajit, R. E. 2010. Kajian Strategis Analisa Cost-Benefit Inverstasi Teknologi Informasi. Yogyakarta: Penerbit Andi.

[9] Syaifullah dan Jony Widianto. 2014. Studi Kelayakan Sistem Informasi Akademik Berbasis Web Pada Poltekes Kemenkes Riau dengan Menggunakan Metode Kelayakan Telos. Jurnal Sains Teknologi dan Industri. Vol. 11. No. 2.

[10] Doerachman, J. D., Kaunang, I. S., Stanley, \& Yaulie. 2012. Analisa Kelayakan Investasi TI Menggunakan Metode Cost Benefit. Jurnal Teknik Informatika Universitas Sam Ratulangi. Vol 1. No 2.

[11] Prabantoro, G. 2003. Mengukur Kelayakan Ekonomis Proyek Sistem Informasi Manajemen menggunakan Metode Cost Benefit dan Aplikasi dengan MS Excel 2000. http://www.geocities.ws/gatot_prabantoro/cost n benefit_analysis.pdf diakses pada 21 November 2016.

[12] H.M.Yacob Ibrahim.,2009. Studi Kelayakan Bisnis Edisi Revisi. Penerbit Rineka Cipta. Jakarta

[13] Siegel, Sidney. (1997). Statistik Non Parametrik untuk Ilmu-ilmu Sosial. Jakarta: PT Gramedia Pustaka Utama

[14] Gaspersz Vincent. 2005. Total Quality Management. Gramedia Pustaka Utama, Jakarta

[15] Subagyo. 1986. Forecasting Konsep dan Aplikasi. Yogyakarta: BPFE

[16] Amir, M. Taufiq. 2005. Dinamika Pemasaran: Jelajahi \& Rasakan. Jakarta: PT. RajaGrafindo Persada.

[17] Parker, Marilyn, Robert J. Benson, H.E. Trainor. Information Economics: Linking Business Performance to Information Technology. New Jersey: Prentice Hall. 1988.

[18] Roth, R.M., Dennis, A., and Barbara Haley Wixom. 2013. Systems Analysis and Design: International Student Version 5th Edition. Singapore. John Wiley \& Sons, Inc

[19] Husein Umar. 2007. Metode Penelitian Untuk Skripsi Dan Tesis Bisnis, Jakarta: PT. Raja Grafindo Persada

[20] Sutrisno, 2001. Manajemen Keuangan Teori, Konsep dan Aplikasi, Edisi Pertama Cetakan Kedua,.Ekonisia, Yogyakarta.

[21] A.Ross, Stephen, Dkk. 2009. Pengantar Keuangan Perusahaan 1. Jakarta: Salemba Empat

[22] Angga Adis Pratama dan Andry Alamsyah. 2013. Studi Kelayakan Sistem Penilaian Essay Dalam Bahasa InggrisSecara Otomatis (Case Study at Telkom University Bandung, MBTI Department, MBTI Internasional Sub-Department). Bandung Penerbit: Universitas Telkom Bandung 